\title{
MOTHERHOOD EXPERIENCE: ADOPTIVE AND BIOLOGICAL MOTHERS
}

\author{
Yulia F. Lakhvich \\ Belarusian State University, Minsk, Republic of Belarus \\ E-mail: luf@tut.by
}

To become a mother ... To be a mother ... What does it mean for a woman? And what else changes her life so irreversibly, allows to see the world in a different way and discovers new, earlier unknown features? Probably, nothing does. However, there is also a question how a woman bearing a child and carrying out motherhood responsibilities and a woman who has not given life to a child, but carrying out the same responsibilities, goes through the process of motherhood. It is one of the questions that was studied in a comparative research of the adaptation process in the Belarusian adoptive and biological families in case of a child appearing in the family. The study involved 64 adoptive and 62 biological mothers.

Thus, what are the differences revealed in the study between adoptive and biological mothers?

To begin with, the differences were found in how mothers from both groups evaluate the nature of their personal child acceptance and its acceptance by other family members.

So, biological mothers testify to a faster emergence of maternal feelings and a little easier acceptance of the child. In other words, it is originally more difficult for a woman to accept an adopted child than a biological one. It is well explained by the specifics of the child appearance in case of adoption. In general, considerable mental and physical load lies down on a biological mother before the child is born, as well as new responsibilities and restrictions that appear in her life. However, an emotional bond with the child is formed much earlier. All this promotes an easier initial child acceptance.

Assessing the nature of a spouse's and other relative's child acceptance mothers in both groups gave similar responses. There was only one exception related to other children in their families, who accepted the baby easier in case of adoption rather than in case of birth. Probably this assessment could be affected by the fact that there were already adopted or foster children in some adoptive families at the time when a new child appeared. These children accepted a new member of the family easier as they have had their own adoption and acceptance experience.

Besides, as the practice shows the adoption decision is as a rule the all-family decision and the "vote" of other children is not the one to ignore. In case of childbirth the opinion of other children in a family is often not taken into account. Parents decide to expand their family and "confront other children with the fact".

The study also shows that there are both similarities and differences in how adoptive and biological mothers evaluate life changes after the child's appearance.

The interesting phenomenon is found in the sphere of mothers' career and professional self-realization. So, adoptive mothers note the positive influence of child's appearance in this sphere much more often than biological mothers. Almost one in three adoptive mothers $(32 \%)$ indicate that, whereas in the group of biological mothers it is done only by one in five (19\%).

At the same time, the sphere of marital relationship was more often a subject to be affected by the child birth rather than adoption. Although about a half of all mothers in both groups indicate the improvement of the marital relations after the child's appearance, there are 
significant distinctions among estimates of other women in the groups. So, biological mothers more often say that their relations with their spouses after the childbirth, at first, worsened, but improved over time.

In their turn, adoptive mothers more often consider that their matrimonial relations are stable and haven't changed with the child's appearance in the family. It can be explained by the following fact: couples that make the adoption decision often have more mature relations, as they have passed the test of time and life testing (including - test by childlessness).

Changes in social contacts of adoptive as well as biological mothers are similar in nature after the child's appearance. Most often both adoptive and biological mothers either deny the existence of any changes or testify to expansion of communication contact community. It is quite an expected result. Indeed, the appearance of the child, regardless of its origin, always entails the need for new contacts with health professionals, teachers as well as a possibility of acquaintance and friendship with other parents (for example, in a kindergarten, in different child groups and clubs and just while having a walk outside).

The general emotional conditions of mothers are exposed to virtually the same changes in both groups. As a rule, it comes to improve their general background of mood. However, adoptive mothers in comparison with biological ones mention deterioration of the health after the child's appearance much less. Perhaps, it is reasoned by the fact that the child's adoption does not include the process of pregnancy and childbirth.

Impact of child's appearance on a family as a whole somewhat differs according to the mothers' estimates from two groups. Adoptive mothers (68\%) noted that the child's appearance brought a new meaning to their lives much more often than biological mothers (53\%). And on the contrary biological mothers more often say about the redistribution of roles in their family after the child's appearance ( $31 \%$ versus $20 \%$ ).

Now let's consider what differences between biological and adoptive mothers during their further interaction with the child exist.

Although originally it is more difficult for adoptive mothers to accept a child further they are more successful in this aspect. The research has shown that they experience more acceptance and less neglect to the child compared with biological mothers. Perhaps, it is caused by the fact that for many adoptive mothers the child is long-awaited. Moreover, initially they are more prone to its unconditional acceptance taking into account the child's special needs, unlike biological mothers who are not always ready for that.

It is also found out that adoptive mothers in comparison with biological mothers are less inclined to use avoidance or leaving strategies in solution of problem situations. It may be indicative of their larger adaptability in terms of overcoming difficult life situations. On the one hand, it is quite clear, considering the difficult life experience of many adoptive mothers, who faced a problem of childlessness and didn't go on the way of its avoiding, and ignoring, choosing an alternative way to the parenthood. On the other hand, a lower tendency to avoid difficult situations, allows adoptive mothers to be more successful in coping with the additional difficulties connected with further raising a non-biological child.

At the same time, it is revealed that adoptive mothers are less characterized by behavioral and psychological flexibility than biological mothers.

Therefore, it is both the strength and the weakness of adoptive mothers. Indeed, less tendency to avoid problems and focus on its constructive solution is a positive adaptation factor, while less flexibility is a preventive factor. This contradiction can become aggravated when time passes and can result in a crisis of satisfaction with the adoptive parent role and relationship with the adopted child. This information is important for those specialists, who accompany an adoptive family.

That's why flexibility as an adoptive mother's personal trait has to become one of the most significant parameters of psychological diagnostics at the stage of adoption readiness evaluation. And further after the adoption it is advisable to pay special attention to the development of adoptive mothers' personal flexibility. One possible solution of this goal is involvement of adoptive parents in clubs, support groups or associations of adoptive parents that will allow them to see various models of the relations in different families, multiple solutions of various problems. 
OF PSYCHOLOGY IN THE $21^{\text {st }}$ CENTURY

Vol. 8, No. 2, 2014

142

The benefits of the above-mentioned information is evidenced by the fact, which is also revealed in the study: adoptive mothers use less communication experience with other parents to solve problems with the child compared with biological mothers. It can indirectly prove that adoptive mothers feel lack of communication exactly with other adoptive parents, but not with parents at all.

Although many of the same changes occur in lives of both adoptive and biological mothers after the child's appearance still there are some specific features of adaptation in each of these groups. Therefore, we can pose and point out the uniqueness of adoptive as well as biological motherhood experience.

Received: December 02, 2014

Accepted: December 15, 2014 